CHRONIC OBSTRUCTIVE PULMONARY DISEASE

\title{
Readmission rates and life threatening events in COPD survivors treated with non-invasive ventilation for acute hypercapnic respiratory failure
}

\author{
C M Chu, V L Chan, A W N Lin, I W Y Wong, W S Leung, C K W Lai
}

Thorax 2004;59:1020-1025. doi: 10.1136/thx.2004.024307

See end of article for authors' affiliations

Correspondence to Dr CM Chu, Division of Respiratory Medicine, Department of Medicine and Geriatrics, United Christian Hospital, Kowloon, Hong Kong SAR, China; chucm@ha.org.hk

Received 5 March 2004 Accepted 11 July 2004

\begin{abstract}
Background: Non-invasive ventilation (NIV) has been shown to reduce intubation and in-hospital mortality in patients with chronic obstructive pulmonary disease (COPD) and acute hypercapnic respiratory failure (AHRF). However, little information exists on the outcomes following discharge. A study was undertaken to examine the rates of readmission, recurrent AHRF, and death following discharge and the risk factors associated with them.

Methods: A cohort of COPD patients with AHRF who survived after treatment with NIV in a respiratory high dependency unit was prospectively followed from July 2001 to October 2002. The times to readmission, first recurrent $A H R F$, and death were recorded and analysed against potential risk factors collected during the index admission.

Results: One hundred and ten patients (87 men) of mean (SD) age 73.2 (7.6) years survived AHRF after NIV during the study period. One year after discharge $79.9 \%$ had been readmitted, $63.3 \%$ had another life threatening event, and $49.1 \%$ had died. Survivors spent a median of $12 \%$ of the subsequent year in hospital. The number of days in hospital in the previous year $(p=0.016)$ and a low Katz score $(p=0.018)$ predicted early readmission; home oxygen use $(p=0.002)$, APACHE II score $(p=0.006)$, and a lower body mass index $(p=0.041)$ predicted early recurrent AHRF or death; the MRC dyspnoea score $(\mathrm{p}<0.001)$ predicted early death.

Conclusions: COPD patients with AHRF who survive following treatment with NIV have a high risk of readmission and life threatening events. Further studies are urgently needed to devise strategies to reduce readmission and life threatening events in this group of patients.
\end{abstract}

$\mathrm{N}$ on-invasive ventilation (NIV) has been shown in randomised controlled trials to improve arterial blood gases and to reduce intubation and in-hospital mortality in patients suffering from exacerbations of chronic obstructive pulmonary disease (COPD) complicated by acute hypercapnic respiratory failure (AHRF) ${ }^{1-7}$ As experience with NIV increases, more severely ill COPD patients are being treated ${ }^{8}$ including those who refuse intubation. ${ }^{9-11}$ While the short term outcome of $\mathrm{NIV}^{1-7}$ and the short and long term outcomes following mechanical ventilation in COPD with AHRF $^{12-19}$ are well established, only a few studies have evaluated the long term outcomes in patients with COPD treated with NIV for AHRF. ${ }^{20-23}$ Most of the studies to date have had small numbers of patients ${ }^{20-22}$ and the focus has mostly been limited to survival. Little is known about the risk factors for poor long term survival and other outcomes such as recurrent AHRF requiring repeat NIV or intubation. Patients with COPD treated with NIV for AHRF appeared to have a high risk of recurrent AHRF in the ensuing year. ${ }^{24}$

We have undertaken a prospective study to obtain comprehensive data on the outcomes following discharge including readmission, recurrent AHRF, and death in a cohort of COPD patients treated with NIV for AHRF. We also sought to explore the risk factors for these adverse outcomes.

\section{METHODS}

\section{Setting}

The United Christian Hospital is a university affiliated acute regional hospital in Hong Kong that serves a population of approximately 500 000. A six bedded NIV unit receives referrals from a 24 hour emergency room, acute medical and geriatric wards, affiliated rehabilitation and long term care facilities for patients with respiratory failure deemed suitable for NIV. The NIV unit is a stand alone unit which is independent of the main multidisciplinary intensive care unit (ICU).

\section{Patients}

From July 2001 to October 2002 consecutive patients admitted to the NIV unit were prospectively screened for recruitment to the study. Patients with AHRF due to COPD, diagnosed according to the American Thoracic Society guideline, ${ }^{25}$ were included if they were successfully treated by NIV and survived to discharge. Patients who required intubation during the admission or who did not survive were not included in the final analysis. AHRF was indicated by a $\mathrm{pH}$ of less than 7.35 with an arterial carbon dioxide tension

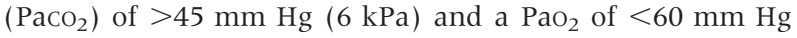
$(8 \mathrm{kPa})$ on room air. Patients with asthma, bronchiectasis, pneumonia, congestive heart failure, or any other non-COPD causes of AHRF were excluded, as were patient with a sleep disordered breathing syndrome requiring home NIV support on discharge-for example, COPD/obstructive sleep apnoea (OSA) overlap syndrome and obesity-hypoventilation syndrome (OHS). A "do not intubate" (DNI) code was not considered a contraindication to NIV. However, the NIV team would discuss with the patients or the surrogates to reach a consensus on whether NIV was appropriate. No patient recruited to the study was given home NIV on discharge as there was inadequate evidence to support its routine use in this group of patients. The study was approved by the institution review board; informed consent was waived. 


\section{Treatment and monitoring}

All patients received the same standard medical treatment with inhaled bronchodilators (salbutamol and ipratropium inhalations), prednisolone $0.5 \mathrm{mg} / \mathrm{kg} / \mathrm{day}$ for 14 days, antibiotics if there was increased sputum volume and purulence (amoxicillin/clavulanate for non-allergic patients or levofloxacin for penicillin allergic patients), hydration, and chest physiotherapy.

NIV was initiated by trained respiratory nurses according to a standardised protocol. ${ }^{26}$ The nurses remained at the bedside during the initial period of acclimatisation. BiPAP Vision (Respironics Inc, Murrysville, PA, USA) was used to provide bi-level pressure support ventilation. Expiratory positive airway pressure (EPAP) was titrated upwards from $4 \mathrm{~cm} \mathrm{H}_{2} \mathrm{O}$ to allow effective triggering. Inspiratory positive airway pressure (IPAP) was titrated to reduce respiratory distress, targeting a respiratory rate of $<25$ breaths/min and a tidal volume of $7-10 \mathrm{ml} / \mathrm{kg}$. The fraction of inspired oxygen $\left(\mathrm{FiO}_{2}\right)$ was titrated to target pulse oximetry oxygen saturation $\left(\mathrm{SpO}_{2}\right)$ to above $90 \%$. The rise time was set to optimise the patient's comfort. A spontaneous/timed mode with a backup rate of $14 / \mathrm{min}$ and an inspiratory time of 1 second was provided. A heated humidifier was used if the patient complained of excessive dryness and a plateau valve (Respironics Inc) was used if the EPAP was below $8 \mathrm{~cm} \mathrm{H}_{2} \mathrm{O}$. Interfacing with different types of nasal or full face masks was individualised according to nursing assessment, with particular attention paid to leakage, mouth breathing, and pressure over the nasal bridge.

NIV was used for as many hours as possible in the first day (typically around 20 hours) with interruptions for food, drinks, communication, inhalation treatment and physiotherapy. If improvement occurred the duration of NIV was gradually reduced. Successful weaning from NIV was defined as a continuous period of complete independence from NIV for more than 48 hours.

Throughout treatment the following parameters were monitored: patient's comfort, synchrony with machine by hourly bedside observation, heart rate, respiratory rate, mental state and $\mathrm{SpO}_{2}$. Arterial blood gas tensions were measured 1 hour after initiation, 4-6 hours after initiation, and at least every 24 hours thereafter or when necessary.

Patients were intubated if they had any of the following characteristics (unless they had a DNI code): lack of clinical improvement with increasing dyspnoea or deterioration in blood gases, haemodynamic instability, uncontrolled ventricular arrhythmias, sputum retention, development of hypercapnic coma, and cardiorespiratory arrest.

All patients who survived were referred to a pulmonary rehabilitation unit (Haven of Hope Hospital) on discharge for pulmonary rehabilitation and optimisation of their medications, nutrition, and home oxygen therapy. All patients were discharged with an inhaled short acting $\beta_{2}$ agonist, anticholinergic drugs, and an inhaled corticosteroid of up to $1000 \mu \mathrm{g}$ beclomethasone or equivalent. Long acting $\beta_{2}$ agonists and tiotropium were not prescribed.

\section{Data collection}

The following were collected at baseline: demographic and anthropometric data, smoking history (pack-years), spirometric data (within 6 months of study), body mass index (BMI), MRC dyspnoea score ${ }^{27} 2$ weeks before admission by patient recall, Katz Activities of Daily Living (ADL) score ${ }^{28}$ 2 weeks before admission by patient recall, Charlson's comorbidity score, ${ }^{29}$ total number of hospital days in the previous year, Acute Physiology and Chronic Health Evaluation (APACHE) II score, ${ }^{30}$ arterial blood gas tensions, blood counts and biochemistry results, the presence of pneumonia and of cor pulmonale, and the initial ventilator settings. If no spirometric data were available within 6 months of the study, spirometric tests were performed when the patient was stabilised, if possible.

If a patient developed more than one episode of AHRF requiring NIV during the study period, the first episode was considered to be the index episode. All subsequent episodes became an outcome of interest and each patient contributed as one case. All survivors were followed for a minimum of 1 year after discharge from the index admission.

The following outcomes were recorded: (1) readmissions due to respiratory causes, (2) development of life threatening events (recurrent AHRF requiring assisted ventilation or death), and (3) death. Time to readmission, time to any life threatening event, and time to death from the discharge date were also recorded, together with the percentage of surviving time spent in hospital in the subsequent year. Being a regional hospital, patients requiring readmission almost always returned to us. Complete follow up of the outcome data was verified using a computerised database provided by the Hong Kong Hospital Authority which covers more than 95\% of hospital services in Hong Kong, as well as telephone follow up.

\section{Data analysis}

Data were expressed as mean (SD) or median (interquartile range, IQR) as appropriate unless otherwise specified. Serial changes in arterial blood gas measurements were analysed by the Friedman's test. All timed data were calculated from the date of discharge. Readmission, event-free survival following discharge and survival were examined using Kaplan-Meier plots and life table analysis. The data were censored at the last follow up visit which was at least 1 year after discharge.

To explore potential risk factors for the various outcomes, the following baseline characteristics were considered in univariate analysis: age, sex, use of home oxygen, BMI, MRC dyspnoea score, Katz ADL score, Charlson's co-morbidity score, smoking status, pack-year history of smoking, previous intubation, previous NIV, forced expiratory volume in 1 second $\left(\mathrm{FEV}_{1}, \%\right.$ predicted $)$, presence of DNI code, number

Table 1 Baseline characteristics of the cohort of COPD survivors treated with non-invasive ventilation for acute respiratory failure $(n=110)$

\begin{tabular}{|c|c|}
\hline \multicolumn{2}{|l|}{ Characteristics } \\
\hline 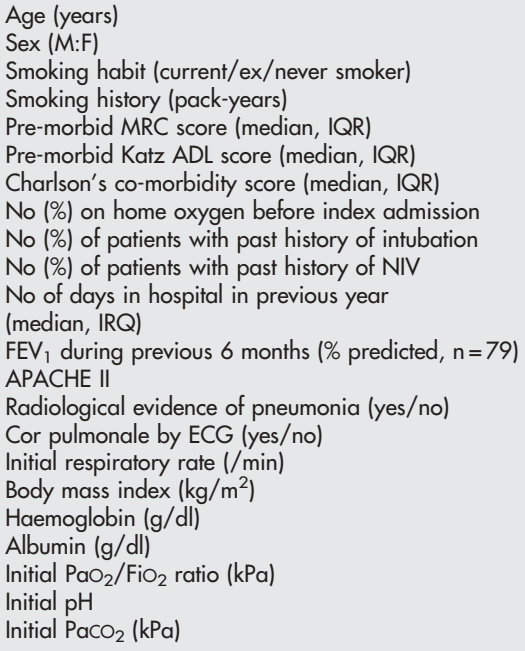 & $\begin{array}{l}73.2(7.6) \\
87: 23 \\
8 / 97 / 5 \\
50(31) \\
4(3-4) \\
5(3.75-6) \\
1(1-2) \\
57(52 \%) \\
15(14 \%) \\
36(33 \%) \\
22.5(4-61.25) \\
33.3(16.6) \\
19.4(4.7) \\
34 / 76 \\
35 / 75 \\
26(6) \\
20.2(4.5) \\
12.7(1.9) \\
32.2(5.4) \\
37.9(19.9) \\
7.24(0.005) \\
11.2(2.6)\end{array}$ \\
\hline $\begin{array}{l}\text { Data are expressed as mean }(S D) \text { unless otherwise sp } \\
\mathrm{IQR}_{1} \text {, interquartile range; } \mathrm{FEV}, \text {, forced expiratory volu } \\
\mathrm{PaO}_{2}, \mathrm{PaCO}_{2} \text {, arterial oxygen and carbon dioxide tens } \\
\text { of inspired oxygen; } \mathrm{ADL} \text {, Activities of Daily Living. }\end{array}$ & $\begin{array}{l}\text { secified. } \\
\text { ions; } 1 \text { in } \mathrm{FiO}_{2} \text {, fraction }\end{array}$ \\
\hline
\end{tabular}


Table 2 Initial settings of non-invasive ventilation and blood gas responses $(n=110)$

\begin{tabular}{ll}
\hline Parameters & \\
\hline IPAP $\left(\mathrm{cm} \mathrm{H}_{2} \mathrm{O}\right)$ & $16.2(2.8)$ \\
EPAP $\left(\mathrm{cm} \mathrm{H} \mathrm{H}_{2} \mathrm{O}\right)$ & $6.2(2.0)$ \\
$\mathrm{FiO}_{2}(\%)$ & $38.6(10.8)$ \\
$\mathrm{No}$ of days on NIV (median, IQR) & $5(3-7)$ \\
First hour & $7.28(0.07)$ \\
$\mathrm{pH}$ & $9.9(2.1)$ \\
$\mathrm{PaCO}_{2}(\mathrm{kPa})$ & $7.34(0.07)$ \\
Day 1 & $9.0(1.9)$ \\
$\mathrm{pH}$ & \\
$\mathrm{PacO}_{2}(\mathrm{kPa})$ & \\
\hline
\end{tabular}

Data are expressed as mean (SD) unless otherwise specified. $I Q R$, interquartile range; IPAP, inspiratory positive airway pressure; EPAP, expiratory positive airway pressure; $\mathrm{PaO}_{2}$, $\mathrm{PaCO}_{2}$, arterial oxygen and carbon dioxide tensions; $\mathrm{FiO}_{2}$ fraction of inspired oxygen.

of days in hospital in the past year, respiratory rate, presence of pneumonia, haemoglobin, white cell count, albumin level, presence of cor pulmonale, APACHE II score, highest IPAP and EPAP levels required, and time on NIV. Binary categorical data were coded 0 for absence of the risk factor and 1 for presence of the risk factor. Continuous variables that were not normally distributed were transformed into categorical variables by dichotomising around the median values. Cox's regression was used to analyse potential risk factors for the various outcomes. Factors associated with the outcomes on univariate analysis with $\mathrm{p}$ values $<0.1$ were further analysed by multivariate Cox's regression with forward selection by the likelihood ratio method. Further models were examined by adding potentially important variables of high hazard ratios that were initially excluded from the first model. A two tailed $\mathrm{p}$ value of $<0.05$ was considered statistically significant. Hazard ratios (HRs) are given with $95 \%$ confidence intervals (95\% CIs). All statistical analyses were performed using statistical software SPSS Version 11.0 (SPSS Inc, Chicago, IL, USA).

\section{RESULTS}

During the 16 month study period the unit received 148 NIV referrals. Thirty non-COPD cases were excluded (seven with pneumonia, six with asthma, five with bronchiectasis, four with acute pulmonary oedema, two with kyphoscoliosis, two with COPD/OSA overlap syndrome, two with OHS, one with neuromuscular disorder, and one with post-tuberculous fibrothorax); eight patients with COPD who died despite NIV (including two who were subsequently intubated) were

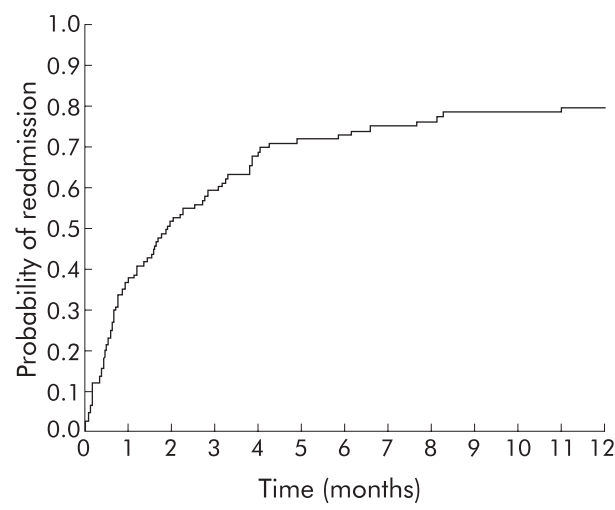

Figure 1 Kaplan-Meier plot showing readmission in patients with COPD who survived an episode of acute hypercapnic respiratory failure treated by non-invasive ventilation.
Table 3 Independent risk factors for adverse outcomes following discharge

\begin{tabular}{|c|c|c|}
\hline $\begin{array}{l}\text { Independent risk factors for } \\
\text { outcomes }\end{array}$ & $\begin{array}{l}\text { Adjusted hazard ratio } \\
(95 \% \mathrm{Cl})\end{array}$ & $p$ value \\
\hline \multicolumn{3}{|l|}{ Readmission } \\
\hline Katz score 0-4 & $1.75(1.10$ to 2.76$)$ & 0.018 \\
\hline $\begin{array}{l}>21 \text { days in hospital in previous } \\
\text { year }\end{array}$ & 1.74 (1.11 to 2.74$)$ & 0.016 \\
\hline \multicolumn{3}{|l|}{ Recurrent life threatening event* } \\
\hline $\begin{array}{l}\text { On long term oxygen before } \\
\text { index admission }\end{array}$ & 2.07 (1.30 to 3.30$)$ & 0.002 \\
\hline $\begin{array}{l}\text { APACHE II score (per } 5 \text { point } \\
\text { increase) }\end{array}$ & 1.34 (1.09 to 1.66$)$ & 0.006 \\
\hline $\begin{array}{l}\text { Body mass index (per } 1 \mathrm{~kg} / \mathrm{m}^{2} \\
\text { increase) }\end{array}$ & $0.93(0.87$ to 0.99$)$ & 0.041 \\
\hline \multicolumn{3}{|l|}{ Death } \\
\hline MRC dyspnoea score 4-5 & $3.07(1.75$ to 5.41$)$ & $<0.001$ \\
\hline
\end{tabular}

*Recurrent life threatening event defined as recurrent acute hypercapnic respiratory failure requiring assisted ventilation or death.

also excluded. Thus, 110 COPD patients with AHRF treated by NIV who survived to discharge were available for analysis. There were 87 men (79\%) and 23 women (21\%) with a mean (SD) age of 73.2 (7.6) years and a mean APACHE II score of 19.5 (4.7). Details of the baseline characteristics of this cohort are shown in table 1. The initial NIV settings, the length of time on NIV, and the arterial blood gas responses are shown in table 2. Steady improvements were seen in the mean $\mathrm{pH}$ $(\mathrm{p}<0.001)$ and $\mathrm{PaCO}_{2}(\mathrm{p}<0.001)$. On discharge, 14 patients (13\%) received newly prescribed home oxygen treatment.

Follow up was complete for the entire cohort of 110 COPD patients with AHRF treated by NIV who survived to discharge. The median follow up time was 403 days. During the follow up period 85 patients were readmitted at least once for respiratory problems. The median number of readmissions in the year following discharge was 2 (range 0-13) and the median (IQR) amount of time spent in hospital during the year was $12(5-29) \%$. The median time to the first readmission was 57 days and the readmission rate at 1 year was 79.9 (71.6-88.2)\%. The Kaplan-Meier plot for readmission is shown in fig 1 . On univariate analysis, a low Katz ADL score (0-4), a higher number of days in hospital in the previous year ( $>21$ days), and a DNI status were associated with early readmission (see table S1 available online at the Thorax website, www.thoraxjnl.com/supplemental). On multivariate analysis a low Katz ADL score (0-4) and a higher

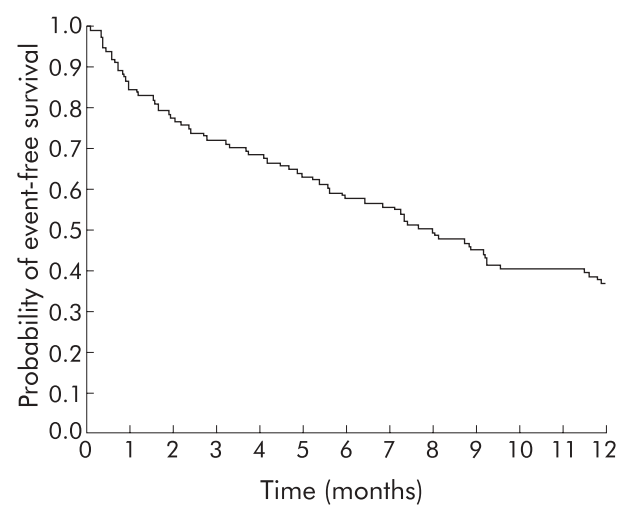

Figure 2 Event-free survival for COPD patients who survived an episode of acute hypercapnic respiratory failure treated by non-invasive ventilation. (Event $=$ death or recurrent respiratory failure requiring assisted ventilation). 


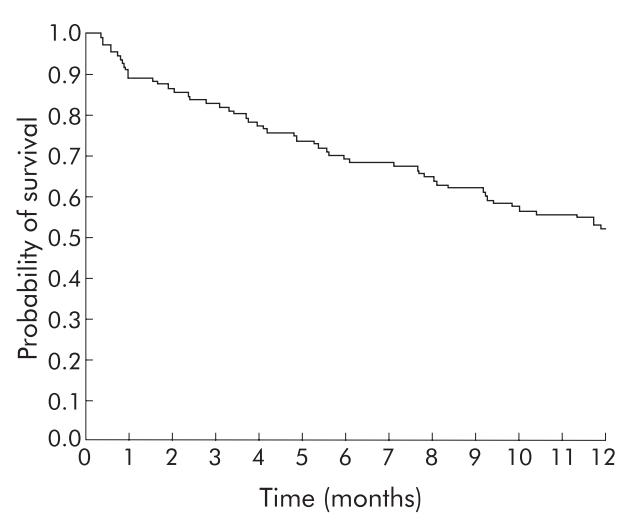

Figure 3 Survival curve for COPD patients who survived an episode of acute hypercapnic respiratory failure treated by non-invasive ventilation.

number of days in hospital in the previous year ( $>21$ days) were independently associated with risk of readmission $(\mathrm{p}=0.018$ and 0.016 , respectively; table 3$)$. DNI status was not independently associated with readmission (see table S2 available online at the Thorax website).

Seventy nine patients had at least one life threatening event during follow up: 64 developed a recurrent episode of AHRF requiring assisted ventilation (62 NIV, two intubations) and 15 died without repeat assisted ventilation. The median event-free survival was 233 days and the 1 year actuarial event-free survival was $36.7(27.2-45.5) \%$-that is, $63.3 \%$ developed a life threatening event. In the first year following discharge 44 patients received repeat NIV for recurrent AHRF: 32 (29\%) had one episode of repeat NIV, five (5\%) had two, five $(5 \%)$ had three, and two $(2 \%)$ had four. The event-free survival curve is shown in fig 2. On univariate analysis, home oxygen use before the index admission, low BMI, high MRC score, low Katz score, DNI status, higher number of days in hospital in the previous year, APACHE II score, and duration of NIV use were associated with a recurrent life threatening event (see table S3 available online at Thorax website). On multivariate analysis using a forward selection method, the following factors were independently associated with a recurrent life threatening event: home oxygen use before index admission $(p=0.002)$, APACHE II score $(p=0.006)$ and BMI $(p=0.041$, table 3$)$. These variables were relatively stable when various multivariate models were examined (see table S4 available online at the Thorax website). However, the potential contribution of other variables such as MRC score, number of days in hospital in previous year, and DNI status could not be entirely excluded as the number of subjects was small compared with the number of variables tested.

Sixty patients died during the follow up period, 54 of whom $(90 \%)$ died of respiratory failure. Other causes of death were septicaemia $(n=2)$, lung cancer $(n=1)$, heart failure with renal failure $(\mathrm{n}=1)$, pancreatitis with multiorgan failure $(n=1)$ and meningitis $(n=1)$. The actuarial survival at 1 year was 50.9 (41.4-60.5)\% (that is, $49.1 \%$ died). The estimated median survival was 411 days. The KaplanMeier plot for survival is shown in fig 3. On univariate analysis, home oxygen use before the index admission, low BMI, a high MRC score (4-5), a low Katz score (0-4), DNI status, and the number of days in hospital in the previous year were associated with early death (see table S5 available online at the Thorax website). On multivariate analysis a high MRC dyspnoea score (4-5) was found to be the only independent risk factor associated with death in patients with COPD after discharge for AHRF treated with NIV $(p<0.001$, table 3$)$. The HR and significance level for the
MRC score remained stable when other potentially important variables were added to the model (see table S6 available online at the Thorax website).

\section{DISCUSSION}

To the best of our knowledge, this is the first sizeable prospective study to follow systematically the various outcomes following discharge of patients with COPD who survived an episode of AHRF after treatment with NIV. This is also the first study to explore the risk factors for adverse outcomes following discharge. COPD patients with AHRF who survive after treatment with NIV have a high risk of readmission and life threatening events. In this study, l year after discharge $79.9 \%$ had been readmitted with respiratory diagnoses, $63.3 \%$ had had another life threatening event, and $49.1 \%$ had died, mainly due to respiratory failure. Survivors spent a median of $12 \%$ of the subsequent year in hospital and a significant proportion required repeated NIV for recurrent AHRF. The findings of this study provide a realistic expectation of the long term outcome after NIV for clinicians and patients, especially as NIV is increasingly being used for more seriously ill COPD patients with AHRF. ${ }^{8}$

While there is little doubt that NIV improves the short term outcome in COPD patients with $\mathrm{AHRF}^{1-7}$ its benefit on the long term outcome is more questionable. In a randomised controlled trial by Plant $e t \mathrm{al}^{23}$ the long term survival rates in patients treated with NIV and a control group given medical treatment were not statistically significant and the survival curves became parallel after the first 3 months. These findings suggest that the benefit of NIV was an improvement in the survival of the acute exacerbation itself. Another study also suggested that the improved long term survival with NIV was attributable to gains in short term survival. ${ }^{21}$ The 1 year mortality of patients with COPD ventilated with NIV for AHRF reported in three small scale studies was $16.7-30 \% .^{20-22}$ In the treatment arm of their randomised controlled trial, Plant $e t a^{23}$ administered NIV to 118 patients with a mean age of 69 years. The 1 year mortality in the NIV arm was 38.4\% and the median survival was 16.8 months.

Our study differed from all the above studies in that the mean age of the patients was higher ( 73 years) and a significant proportion of patients $(32 \%)$ had a DNI code. It is therefore not surprising that the 1 year mortality in our study is higher. This is in line with the reported observation that NIV units are treating more seriously ill patients as the experience grows. ${ }^{8}$ Our study probably reflects the "real life" scenario of similar NIV units. In contrast to controlled trials, ${ }^{20-23}$ patients with a DNI code were not excluded from our study. Patients with COPD who carry a DNI code have a higher burden of disease and are known to have a worse outcome after NIV treatment for AHRF. ${ }^{24}$ Nevertheless, in our study a DNI code was not an independent factor predicting death. Our study also differs from previous studies in that it examines the outcomes of the survivors after NIV, whereas the outcome variables in other series usually included inpatient mortality.

In addition to death, readmission to hospital and recurrent AHRF in patients with COPD also have important implications to both the patients themselves and the healthcare system. Vitacca et $_{\text {al }}{ }^{20}$ reported readmission of 3 of 24 patients to the ICU during the post-discharge follow up period after NIV for AHRF (0.12 patient/year). Bardi et al ${ }^{22}$ also reported repeat NIV in two of 14 patients after the index episode of NIV for AHRF. Both studies had relatively small numbers of subjects and no evaluation of risk factors was made. Our study indicates that readmission and recurrent life threatening events are common in patients with COPD who have survived an episode of AHRF after treatment with NIV. Survivors also spend a substantial proportion of their 
subsequent year in hospital. High readmission rates are also reported in various studies of COPD exacerbations requiring hospitalisation or admission to the ICU. ${ }^{31-34}$

Comparisons of the outcomes of COPD patients suffering from AHRF treated with NIV versus invasive ventilation are difficult because of the different treatment received, the inherent differences in the characteristics of the patients, and the differences in outcome measurements. In general, the reported 1 year mortality ranges from 23\% to 59\%. ${ }^{13} 15183132$ In our study the 1 year survival of $49.1 \%$ is broadly similar to the other studies of acute respiratory failure in patients with COPD treated in the ICU. However, this comparison must be interpreted with caution. Firstly, not all COPD patients in these other studies received assisted ventilation. Secondly, patients who receive NIV for AHRF are likely to be composed of two subgroups that are very different from those who receive intubation for AHRF: (1) patients who have less severe disease so that NIV is appropriate and (2) patients with very poor general health so that intubation is not acceptable.

We have explored potential predictors for the various adverse outcomes after discharge. Factors that indicate severe disease and poor chronic health such as admission to hospital in the past year, low ADL score, home oxygen use, low BMI, a high APACHE II score, and a high MRC dyspnoea score are associated with poor outcomes following discharge. A few observations deserve further discussion. Firstly, a low BMI appeared to predict recurrent life threatening events in our cohort and was also of borderline significance in predicting death. This is in line with a recent report which showed that BMI (cut off $21 \mathrm{~kg} / \mathrm{m}^{2}$ ) is an important factor in a multidimensional grading system of COPD prognosis. ${ }^{35}$ It should be noted that the mean BMI in our cohort was low $(20 \mathrm{~kg} /$ $\mathrm{m}^{2}$ ) and our result should not be extrapolated to morbidly obese patients. Secondly, a worse MRC dyspnoea score was the most important predictor of death in our cohort. This also agrees with the recently proposed COPD grading system that predicts prognosis. ${ }^{35}$ Thirdly, a DNI status was associated with all three adverse outcomes on univariate analysis but it was not an independent factor in multivariate models. This reflects the fact that patients with a DNI code are those who have a combination of poor prognostic indicators. Lastly, the number of potential variables was large in comparison with the sample size. Variables excluded from the multivariate model might have a potentially important effect which was not detected in this study because of limited statistical power.

Few available treatments have been shown to improve the adverse outcomes after NIV for AHRF in patients with COPD. Long term oxygen therapy is the only treatment reported to prolong survival in COPD in controlled trials. ${ }^{36}{ }^{37}$ The role of inhaled corticosteroids in improving survival in COPD has not been established. ${ }^{38}$ For the subgroup of COPD patients who developed AHRF requiring acute NIV treatment, even less is known regarding effective treatment to improve these adverse outcomes. Uncontrolled data suggest that home NIV might reduce both hospital admissions and clinic visits in patients with severe COPD with AHRF. Jones et $a l^{39}$ gave home NIV treatment to 11 patients with severe stable COPD with chronic hypercapnia who did not respond to conventional treatment and found that hospital admissions and clinic visits were halved in the subsequent year, together with a sustained improvement in arterial blood gas tensions. Another uncontrolled study suggested that domiciliary NIV for a highly selected group of COPD patients with recurrent admissions requiring NIV is effective at reducing costs, number of days in hospital, readmissions, days in the ICU, and clinic visits. ${ }^{40}$ However, the results of randomised controlled trials are controversial. Of four early randomised controlled trials on the use of NIV in severe stable COPD, ${ }^{41-44}$ only one had a positive result. ${ }^{41}$ However, these four trials have been criticised for including patients with chronic stable COPD who were not sufficiently hypercapnic to benefit from home NIV, for using inadequate inflation pressures, inadequate patient acclimatisation time, and not selecting the optimal outcome variables. ${ }^{45}$ In the most recent randomised controlled trial a statistically significant improvement in daytime $\mathrm{PaCO}_{2}$ in the NIV group compared with the control group was found; there were also trends towards reduced total hospital admissions and ICU admissions in the home NIV group, but the results were not statistically significant. ${ }^{46}$

Our study showed that a significant proportion of patients with COPD treated by NIV for AHRF would suffer another life threatening event in the following year. These patients could form the basis for a future randomised trial of home NIV. We propose that hospital readmission, recurrent AHRF, and death are important end points to be examined in future randomised controlled trials. We also propose that baseline characteristics identified in this study which predict adverse outcomes should be measured in future trials. The identification of patients with adverse baseline characteristics allows future studies to target the high risk group to reduce poor outcomes following discharge.

This study has several limitations. Firstly, it was performed at a single centre, but we believe our sample could reflect the typical patterns in similar NIV units. Secondly, as there has been no similar previous study, we sought to explore a wide range of plausible explanatory variables. The number of variables examined was large in comparison with the sample size. We could not entirely exclude the potential contributions of some of the excluded but important variables, given the limited statistical power. However, we believe our study does provide a preliminary picture of the type of risk factors that are important. Thirdly, the period of inclusion lasted 16 months but not a full yearly period ( 1 or 2 years). This might introduce inaccuracies to the estimates of the various outcomes as there are seasonal variations in the frequency of COPD exacerbations. This was unfortunate as the study was interrupted by a drastic and unplanned reorganisation of services due to the sudden appearance of the severe acute respiratory syndrome epidemic in Hong Kong. However, we believe this does not change our main conclusion that COPD patients with AHRF who survive after treatment with NIV have a high risk of readmission and life threatening events in the subsequent years. Further studies are urgently needed to devise strategies to reduce readmission and life threatening events in this group of patients. The results obtained in this study provide important information for the design of future randomised controlled studies.

\section{ACKNOWLEDGEMENTS}

The authors thank Mr Stephan An of Patient Statistics Section, United Christian Hospital, Hospital Authority in the search of the territory-wide outcome data and the respiratory nurses in the NIV unit for taking care of the patients during the study.

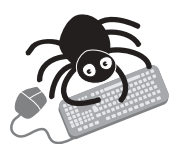

Tables S1-S6 are available online at www.thoraxinl. $\mathrm{com} /$ supplemental.

\section{Authors' affiliations}

C M Chu, V L Chan, A W N Lin, W S Leung, Division of Respiratory Medicine, Department of Medicine and Geriatrics, United Christian Hospital, Hong Kong

I W Y Wong, Pulmonary Unit, Haven of Hope Hospital, Hong Kong

C K W Lai, Department of Medicine and Therapeutics, Chinese University of Hong Kong, Hong Kong

Financial support: none. 


\section{REFERENCES}

1 Bott J, Carroll MP, Conway JH, et al. Randomised controlled trial of nasal ventilation in acute ventilatory failure due to chronic obstructive airways disease. Lancet 1993;341:1555-7.

2 Brochard L, Mancebo J, Wysocki M, et al. Noninvasive ventilation for acute exacerbations of chronic obstructive pulmonary disease. N Engl J Med 1995;333:817-22.

3 Kramer N, Meyer TJ, Meharg J, et al. Randomized, prospective trial of noninvasive positive pressure ventilation in acute respiratory failure. Am J Respir Crit Care Med 1995;151:1799-806.

4 Angus RM, Ahmed AA, Fenwick $\sqcup$, et al. Comparison of the acute effects on gas exchange of nasal ventilation and doxapram in exacerbations of chronic obstructive pulmonary disease. Thorax 1996;51:1048-50.

5 Celikel T, Sungur M, Ceyhan B, et al. Comparison of noninvasive positive pressure ventilation with standard medical therapy in hypercapnic respiratory failure. Chest 1998;114:1636-42.

6 Martin TJ, Hovis JD, Costantino JP, et al. A randomised prospective evaluation of non-invasive ventilation for acute respiratory failure. Am J Respir Crit Care Med 2000;161:807-13.

7 Plant PK, Owen JL, Elliot MW. Early use of non-invasive ventilation for acute exacerbations of chronic obstructive pulmonary disease on general respiratory wards: a prospective multicentre randomised controlled trial. Lancet 2000;355: 1931-5.

8 Carlucci A, Delmastro M, Rubini F, et al. Changes in the practice of noninvasive ventilation in treating COPD patients over 8 years. Intensive Care Med 2003;29:419-25

9 Benhamou D, Girault C, Faure C, et al. Nasal mask ventilation in acute respiratory failure. Experience in elderly patients. Chest 1992;102:912-7.

10 Freichels TA. Palliative ventilatory support: use of noninvasive positive pressure ventilation in terminal respiratory insufficiency. Am J Crit Care 1994;3:6-10

11 Meduri GU, Fox RC, Abou-Shala N, et al. Noninvasive mechanical ventilation via face mask in patients with acute respiratory failure who refused endotracheal intubation. Crit Care Med 1994;22:1584-90.

12 Kaelin RM, Assimacopoulos A, Chevrolet JC. Failure to predict six-month survival of patients with COPD requiring mechanical ventilation by analysis of simple indices. A prospective study. Chest 1987;92:971-8.

13 Stauffer JL, Fayter NA, Graves B, et al. Survival following mechanical ventilation for acute respiratory failure in adult men. Chest 1993; 104:1222-9.

14 Nava S, Rubini F, Zanotti E, et al. Survival and prediction of successful ventilator weaning in COPD patients requiring mechanical ventilation for more than 21 days. Eur Respir J 1994;7:1645-52.

15 Seneff MG, Wagner DP, Wagner RP, et al. Hospital and 1-year survival of patients admitted to intensive care units with acute exacerbation of chronic obstructive pulmonary disease. JAMA 1995;274:1852-7.

16 Moran JL, Green JV, Homan SD, et al. Acute exacerbations of chronic obstructive pulmonary disease and mechanical ventilation: a reevaluation. Crit Care Med 1998;26:71-8.

17 Nevins ML, Epstein SK. Predictors of outcome for patients with COPD requiring invasive mechanical ventilation. Chest 2001;119:1840-9.

18 Breen D, Churches T, Hawker F, et al. Acute respiratory failure secondary to chronic obstructive pulmonary disease treated in the intensive care unit: a long term follow up study. Thorax 2002;57:29-33.

19 Afessa B, Morales IJ, Scanlo PD, et al. Prognostic factors, clinical course, and hospital outcome of patients with chronic obstructive pulmonary disease admitted to an intensive care unit for acute respiratory failure. Crit Care Med 2002;30:1610-5

20 Vitacca M, Clini E, Rubini F, et al. Non-invasive ventilation in severe chronic obstructive lung disease and acute respiratory failure: short- and long-term prognosis. Intensive Care Med 1996:22:94-100.

21 Confalonieri M, Parigi P, Scartabellati A, et al. Noninvasive mechanical ventilation improves the immediate and long-term outcome of COPD patients with acute respiratory failure. Eur Respir J 1996;9:422-30.

22 Bardi G, Pierotello $R$, Desideri $M$, et al. Nasal ventilation in COPD exacerbations: early and late results of a prospective, controlled study. Eur Respir J 2000;15:98-104
23 Plant PK, Owen JL, Elliot MW. Non-invasive ventilation in acute exacerbations of chronic obstructive pulmonary disease: long term survival and predictors of in-hospital outcome. Thorax 2001;56:708-12.

24 Chu CM, Chan VL, Wong IWY, et al. Non-invasive ventilation in patients with acute hypercapnic exacerbation of chronic obstructive pulmonary disease who refused endotracheal intubation. Crit Care Med 2004;32:372-7.

25 American Thoracic Society. Standards for the diagnosis and care of patients with chronic obstructive pulmonary diseases. Am J Respir Crit Care Med 1995; 152:S77-120.

26 Mehta S, Hill NS. Noninvasive ventilation. Am J Respir Crit Care Med 2001;163:540-77.

27 Fletcher CM Chairman. Standardised questionnaire on respiratory symptoms: a statement prepared and approved by the MRC Committee on the Aetiology of Chronic Bronchitis (MRC breathlessness score). BMJ 1960;2:1665.

28 Katz S, Akpom CA. Index of ADL. Med Care 1976;14(5 Suppl):116-8.

29 Charlson ME, Pompei P, Ales KL, et al. A new method of classifying prognostic comorbidity in longitudinal studies: development and validation. J Chron Dis 1987;40:373-83.

30 Knaus WA, Draper EA, Wagner DP, et al. APACHE II: a severity of disease classification. Crit Care Med 1985;13:818-29.

31 Connors AF, Dawson NV, Thomas C, et al. Outcomes following acute exacerbations of severe chronic obstructive lung disease. Am J Respir Crit Care Med 1996;154:959-67.

32 Groenewegen KH, Schols AMWJ, Wouters EFM. Mortality and mortalityrelated factors after hospitalization for acute exacerbation of COPD. Chest 2003; 124:459-67.

33 Roberts CM, Lowe D, Bucknall CE, et al. Clinical audit indicators of outcome following admission to hospital with acute exacerbation of chronic obstructive pulmonary disease. Thorax 2002:57:137-41.

34 Garcia-Aymerich J, Farrero E, Félez MA, et al. Risk factors of readmission to hospital for a COPD exacerbation: a prospective study. Thorax 2003;58:100-5.

35 Celli BR, Cote CG, Marin JM, et al. The body-mass index, airflow obstruction, dyspnea, and exercise capacity index in chronic obstructive pulmonary disease. N Eng J Med 2004;350:1005-12.

36 Nocturnal Oxygen Therapy Trial Group. Continuous or nocturnal oxygen therapy in hypoxemic chronic obstructive lung disease: a clinical trial. Ann Intern Med 1980:93:391-8.

37 Medical Research Council Working Party. Long-term domiciliary oxygen therapy in chronic hypoxia and cor pulmonale complicating chronic bronchitis and emphysema. Lancet 1981;1:681-6.

38 Bourbeau J. Inhaled corticosteroids and survival in chronic obstructive pulmonary disease. Eur Respir J 2003;21:202-3.

39 Jones SE, Packham S, Hebden M, et al. Domiciliary nocturnal intermittent positive pressure ventilation in patients with respiratory failure due to severe COPD: long term follow up and effect on survival. Thorax 1998;53:495-8.

40 Tuggey JM, Plant PK, Elliott MW. Domiciliary non-invasive ventilation for recurrent acidotic exacerbations of COPD: an economic analysis. Thorax 2003;58:867-71

41 Strumpf DA, Millman RP, Carlisle CC, et al. Nocturnal positive-pressure ventilation via nasal mask in patients with severe chronic obstructive pulmonary disease. Am Rev Respir Dis 1991;144:1234-9.

42 Meecham Jones DJ, Paul EA, Jones PW, et al. Nasal pressure support ventilation plus oxygen compared with oxygen therapy alone in hypercapnic COPD. Am J Respir Crit Care Med 1995; 152:538-44.

43 Lin CC. Comparison between nocturnal nasal positive pressure ventilation combined with oxygen therapy and oxygen monotherapy in patients with severe COPD. Am J Respir Crit Care Med 1996;154:353-8.

44 Gay PC, Hubmayr RD, Stroetz RW. Efficiency of nocturnal nasal ventilation in stable, severe chronic obstructive pulmonary disease during a 3-month controlled trial. Mayo Clin Proc 1996;71:533-42.

45 Elliot MW, Hill NS. Noninvasive ventilation in severe stable chronic obstructive pulmonary disease. In: Hill NS, ed. Noninvasive positive pressure ventilation: principles and applications. New York: Futura Publishing Company, 2001:145-68.

46 Clini E, Sturani C, Rossi A, et al. The Italian multicentre study on noninvasive ventilation in chronic obstructive pulmonary disease patients. Eur Respir $J$ 2002;20:529-38. 